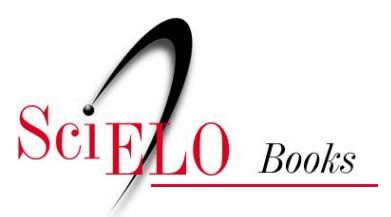

\title{
Ordem Syngnathiformes
}

\author{
Ana Cristina Teixeira Bonecker \\ Claudia Akemi Pereira Namiki \\ Márcia Salustiano de Castro \\ Paula Nepomuceno Campos
}

\section{SciELO Books / SciELO Livros / SciELO Libros}

BONECKER, ACT., et al. Ordem Syngnathiformes. In Catalogo dos estágios iniciais de desenvolvimento dos peixes da bacia de Campos [online]. Curitiba: Sociedade Brasileira de Zoologia, 2014, pp. 169-174. Zoologia: guias e manuais de identificação series. ISBN 978-85-98203-10-2.

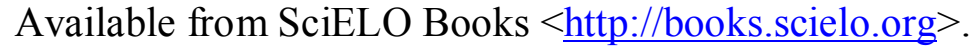

\section{(c) (1)(2)}

All the contents of this chapter, except where otherwise noted, is licensed under a Creative Commons Attribution-Non Commercial-ShareAlike 3.0 Unported.

Todo o conteúdo deste capítulo, exceto quando houver ressalva, é publicado sob a licença Creative Commons Atribuição Uso Não Comercial - Partilha nos Mesmos Termos 3.0 Não adaptada.

Todo el contenido de este capítulo, excepto donde se indique lo contrario, está bajo licencia de la licencia Creative Commons Reconocimento-NoComercial-CompartirIgual 3.0 Unported. 


\section{ORDEM SYNGNATHIFORMES}

A ordem Syngnathiformes é formada por 11 famílias com 278 espécies. Possuem placas dérmicas que recobrem o corpo e a boca é normalmente pequena.

Nesse estudo a ordem Syngnathiformes é representada pelas famílias Fistulariidae e Syngnathidae. 


\section{Família Fistulariidae}

A família Fistulariidae é marinha e ocorre nos oceanos Atlântico, Índico e Pacífico. Compreende um gênero com quatro espécies. O corpo é muito alongado apresentando espinhos minúsculos e o focinho é longo e tubular. Nos exemplares maiores os dois raios centrais da nadadeira caudal formam um filamento longo. As nadadeiras dorsal e anal estão localizadas na parte posterior do corpo.

No Brasil já foram identificadas duas espécies nas fases de larva e adulto: Fistularia petimba Lacepède, 1803 e Fistularia tabacaria Linnaeus, 1758. Nesse estudo é contemplada a espécie Fistularia tabacaria. 


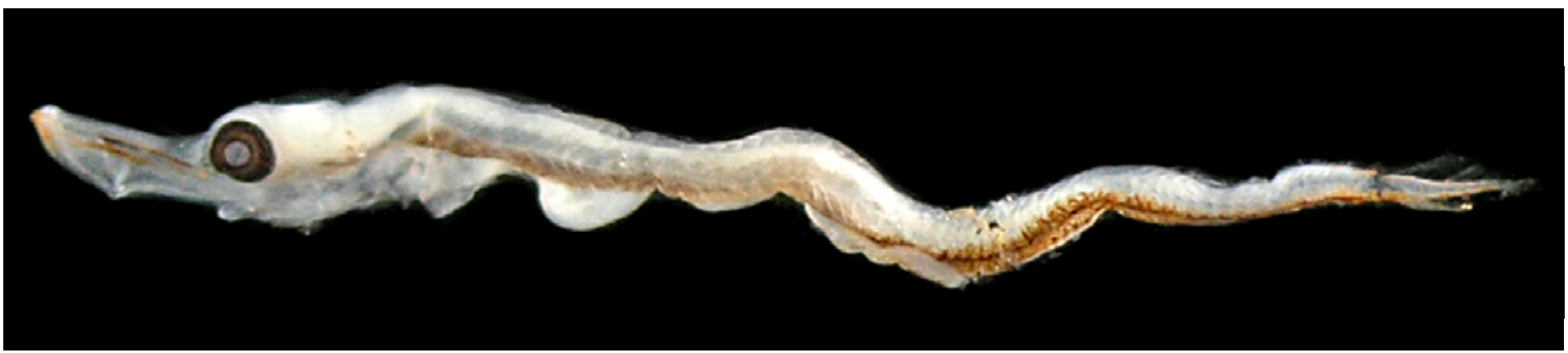

Figura 98: Fistularia tabacaria. DZUFRJ 25043; Pré-flexão; CP 7,2 mm.

\section{Fistularia tabacaria Linnaeus, 1758}

A principal característica para a identificação dessa espécie é o padrão de pigmentação, que acompanha toda a região ventral da larva e pode ser observado em vários estágios do desenvolvimento. Os exemplares menores possuem uma linha contínua de pigmento na região ventral desde a cabeça até a cauda. À medida que a larva cresce esses pigmentos formam uma linha pontilhada ao longo de toda a região ventral e no focinho. $O$ intestino termina na região mediana do corpo, antes da origem das nadadeiras dorsal e anal. O número de miômeros varia entre 75 e 88.

Tamanho: pré-flexão 5,5 mm.

Habitat: espécie de águas salobras e marinhas, demersal. Ocorre em áreas de formações coralinas sobre fundos duros e rochosos em 36 $\mathrm{m}$ de profundidade.

Nome vulgar: Cachimbau azul.

\section{Georreferencimento}

\begin{tabular}{|c|c|c|c|c|c|c|c|c|}
\hline DZUFRJ & Latitude (S) & Longitude (W) & Data & $\begin{array}{c}\text { Tipo de } \\
\text { arrasto }\end{array}$ & $\begin{array}{c}\text { Profundidade } \\
\text { de coleta }\end{array}$ & Rede & $\begin{array}{c}\text { Malha } \\
\text { ( } \boldsymbol{\mu m})\end{array}$ & $\begin{array}{c}\mathbf{N}^{\circ} \text {. de } \\
\text { inds. }\end{array}$ \\
\hline 458 & $22^{\circ} 38^{\prime} 25,0^{\prime \prime}$ & $040^{\circ} 17^{\prime} 41,0^{\prime \prime}$ & $19 / 05 / 2002$ & oblíquo & $40 \mathrm{~m}$ & bongô & 330 & 1 \\
\hline
\end{tabular}

Referências: Barros et al., 2006a; Ditty et al., 2006d; Barros et al., 2007; Fahay, 2007. 


\section{Família Syngnathidae}

A família Syngnathidae possui representantes marinhos, estuarinos e de água doce, incluindo 52 gêneros e aproximadamente 232 espécies. Ocorre nos oceanos Atlântico, Índico e Pacífico. Os adultos de Syngnathidae são pequenos e alcançam no máximo $65 \mathrm{~cm}$. O corpo é envolto por uma série de anéis ósseos articulados. Possuem uma nadadeira dorsal formada apenas por raios, nadadeira anal reduzida ou inexistente e nadadeira pélvica ausente. As aberturas branquiais são reduzidas.

Esta família é dividida em duas subfamílias: Syngnathinae (peixes-cachimbo) e Hippocampinae (cavalos-marinhos). Nesse estudo só foram registrados representantes da subfamília Syngnathinae. Nos peixes-cachimbo os eixos longitudinais da cabeça e do tronco são paralelos, a cauda é reta e não preênsil (com exceção do gênero Acentronura), nadadeira caudal presente.

No Brasil já foram identificadas 13 espécies nas fases de larva e adulto. Nesse estudo são contempladas as espécies Micrognathus crinitus e Micrognathus erugatus. 


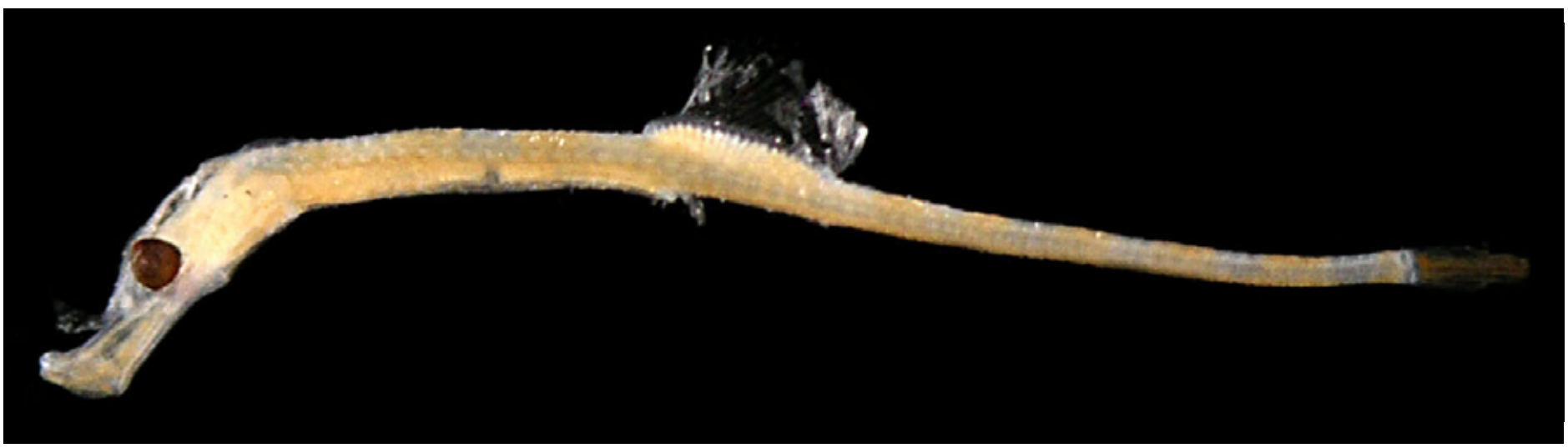

Figura 99: Micrognathus crinitus. A. DZUFRJ 374; CP 8,0 mm.

\section{Micrognathus crinitus (Jenyns, 1842)}

Possui focinho curto com crista mediana dorsal um pouco elevada. As cristas do tronco (dorsal) e da cauda são interrompidas próximo à parte posterior da nadadeira dorsal. A crista inferior do tronco termina no anel anal. As cristas são proeminentes e denticuladas. Possui nadadeira anal. A nadadeira caudal possui 10 raios, a nadadeira dorsal menos de 30 raios e as nadadeiras peitorais $12-14$ raios. Apresenta $17-18$ anéis no tronco; 32-35 anéis da cauda e o número total de anéis é 49-52. As duas espécies registradas são separadas pela diferença no número de anéis e pelas cristas que podem ser proeminentes e denticuladas ( $M$. crinitus) ou não (M. erugatus).

Habitat: espécie marinha, demersal, associada a formações coralinas, ocorre até $21 \mathrm{~m}$ de profundidade.

Tamanho: 8,0 mm.

Nome vulgar: Peixe cachimbo preto.

\section{Georreferencimento}

\begin{tabular}{|c|c|c|c|c|c|c|c|c|}
\hline DZUFRJ & Latitude (S) & Longitude (W) & Data & $\begin{array}{c}\text { Tipo de } \\
\text { arrasto }\end{array}$ & $\begin{array}{c}\text { Profundidade } \\
\text { de coleta }\end{array}$ & Rede & $\begin{array}{c}\text { Malha } \\
(\boldsymbol{\mu m})\end{array}$ & $\begin{array}{c}\mathbf{N}^{\circ} \text {. de } \\
\text { inds. }\end{array}$ \\
\hline 353 & $22^{\circ} 32^{\prime} 03,0^{\prime \prime}$ & $040^{\circ} 17^{\prime} 21,0^{\prime \prime}$ & $19 / 05 / 2002$ & oblíquo & $30 \mathrm{~m}$ & bongô & 330 & 1 \\
\hline 374 & $22^{\circ} 33^{\prime} 477^{\prime \prime}$ & $040^{\circ} 12^{\prime} 25^{\prime \prime}$ & $17 / 05 / 2002$ & oblíquo & $50 \mathrm{~m}$ & bongô & 330 & 1 \\
\hline 375 & $22^{\circ} 38^{\prime} 25,0^{\prime \prime}$ & $040^{\circ} 17^{\prime} 41,0^{\prime \prime}$ & $19 / 05 / 2002$ & oblíquo & $40 \mathrm{~m}$ & bongô & 500 & 2 \\
\hline 654 & $22^{\circ} 38^{\prime} 25,0^{\prime \prime}$ & $040^{\circ} 17^{\prime} 41,0^{\prime \prime}$ & $19 / 05 / 2002$ & oblíquo & $40 \mathrm{~m}$ & bongô & 330 & 1 \\
\hline
\end{tabular}

Referências: Dawson \& Vari, 1982; Barros et al., 2006a; Frias-Torres, 2006b. 


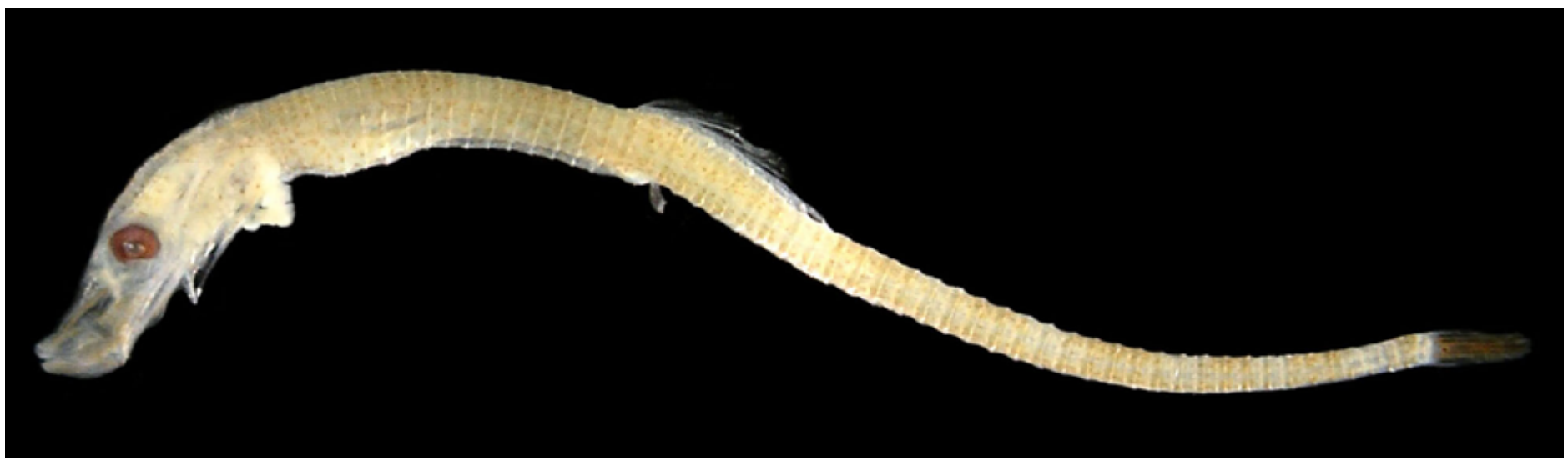

Figura 100: Micrognathus erugatus. A. DZUFRJ 446; CP 12,5 mm.

\section{Micrognathus erugatus Herald \& Dawson, 1974}

Possui focinho curto com quatro a cinco espinhos hialinos diminutos. As cristas do tronco (dorsal) e da cauda são interrompidas próximo à parte posterior da nadadeira dorsal. A crista inferior do tronco termina no anel anal. As cristas são indistinguíveis e essencialmente inteiras. Possui nadadeira anal. A nadadeira caudal possui 10 raios, a nadadeira dorsal menos de 30 raios e as nadadeiras peitorais 12-14 raios. Apresenta 20 anéis no tronco, 36 anéis na cauda e o número total de 56 anéis.

Tamanho: $12,5 \mathrm{~mm}$.

Habitat: espécie marinha e demersal.

Nome vulgar: Peixe cachimbo estrela.

\section{Georreferencimento}

\begin{tabular}{|c|c|c|c|c|c|c|c|c|}
\hline DZUFRJ & Latitude (S) & Longitude (W) & Data & $\begin{array}{c}\text { Tipo de } \\
\text { arrasto }\end{array}$ & $\begin{array}{c}\text { Profundidade } \\
\text { de coleta }\end{array}$ & Rede & $\begin{array}{c}\text { Malha } \\
\text { ( } \boldsymbol{\mu m} \text { ) }\end{array}$ & $\begin{array}{c}\mathbf{N}^{\circ} \text {. de } \\
\text { inds. }\end{array}$ \\
\hline 446 & $22^{\circ} 38^{\prime} 29,0^{\prime \prime}$ & $040^{\circ} 17^{\prime} 40,0^{\prime \prime}$ & $18 / 05 / 2002$ & oblíquo & $800 \mathrm{~m}$ & cilíndrico-cônica & 500 & 1 \\
\hline
\end{tabular}

Referências: Dawson \& Vari, 1982; Barros et al., 2006a; Frias-Torres, 2006b. 